\title{
Comparative phytochemical screening and microbiocidal activity of different parts of Mimosa pudica $\mathbf{L}$.
}

Kuntal Das», M. Jayalakshmi, Kingsly Dass, Maithili Sinha, Milan Bahadur Chand and Mohammad Ismael Fadil Jowaheer Department of Pharmacognosy and Phytochemistry, Krupanidhi College of Pharmacy, Chikkabelandur, Carmelaram Post, Varthur Hobli, Bengaluru-560035, Karnataka, India

\section{Article Info}

Article history

Received 11 September 2021

Revised 28 October 2021

Accepted 30 October 2021

Published Online 30 December 2021

\section{Keywords}

Cultural condition

Phytochemicals

Mimosa pudica $\mathrm{L}$.

MIC

$\mathrm{MBC}$

Microbial study

\begin{abstract}
The present study was aimed with the potential antimicrobial activity in terms of antibacterial and antifungal activities of Mimosa pudica L. (MP) whole parts collected from two different cultural conditions, viz., West Bengal (WB) and Tamil Nadu (TN). The plant parts like roots, stems, leaves and flowers are collected separately and further directly extracted with ethanol, aqueous and hydroalcoholic mixture (2:1). The resulting extracts were subjected with qualitative phytochemical screening, estimation of yield content followed by their antibacterial activity. Antibacterial activity was performed against two Gram positive bacteria, namely; Bacillus subtilis ATCC 6633, Straphylococcus aureus ATCC 29726, and two Gram-negative bacteria, Pseudomonas aeruginosa ATCC 25619, and Escherichia coli ATCC 8739. Phytochemical analysis of extracts revealed the presence of various group of compounds, namely; alkaloids, flavonoids, saponins, sterols, flavonoids, tannins and glycosides. MIC's ranged from 19.2 to 34.6 $\mu \mathrm{g} / \mathrm{ml}$ and $\mathrm{MBC}$ of 19.8 and $33.7 \mu \mathrm{g} / \mathrm{ml}$ except P. aeruginosa which as less sensitive and its MBC reached to $36.7 \mu \mathrm{g} / \mathrm{ml}$ of MP collected from respective places. The antibacterial study demonstrated that methanol root extract was able to inhibit the maximum growth $(p<0.05)$ of both $S$. aureus and $E$. coli for both samples (WB and TN) when compared with amoxicillin. The both activities were significantly different for both the samples. Antibacterial activity was more with roots followed by leaves, flowers and stem for sample collected from WB, whereas the same activity was significantly higher with leaves extract followed by flower, roots and stem extracts of MP collected from TN. The present study concluded that MP has potential antimicrobial activity but the activity depends on the geographical location and with the other environmental conditions.
\end{abstract}

\section{Introduction}

Herbalism involves the use of plants for medicinal purposes. India is a land of agriculture and the hub of medicinal plants. The quest for traditional natural herbs with medicinal properties continues to receive attention as scientists are in need of natural sources, especially ethnobotanical significance for a complete range of biological activities of the plants which ranges from simple fever to chronic diseases such as viral, cancer, etc. Therefore, all the causes and remedies are present in nature. Such a very common and serious one of the diseases causes by microorganisms. They are freely available in nature and can easily reach food during harvesting, processing, and packaging of the plant products and also food products (Hatab et al., 2016). As a result, they cause food spoilage with many health related issues along with has been a significant safety concern to public health (Kirk et al., 2017). There are many synthetic or chemical drugs available in market which are effective for certain time period but due to drug resistance or due to many unwanted side effects, people are rely on natural based products, i.e., herbal sources which are less toxic or having minimal side effects.

\footnotetext{
Corresponding author: Dr. Kuntal Das

Professor, Department of Pharmacognosy and Phytochemistry, Krupanidhi College of Pharmacy, Chikkabelandur, Carmelaram Post, Varthur Hobli, Bengaluru-560035, Karnataka, India

E-mail: drkkdsd@gmail.com

Tel.: +91-9632542846
}

Copyright $($ C) 2021 Ukaaz Publications. All rights reserved.

Email: ukaaz@yahoo.com; Website: www.ukaazpublications.com
Of late, Mimosa pudica L. (MP) belongs to the family Fabaceae, is a creeping annual or perennial herb. The plant is widely available throughout the temperate zones especially in the road sides of India. The plant is well known as sensitive plant, shame plant, sleeping grass, touch me not, and many other names with having fascinating behavior (Kumar et al., 2009). Traditionally, whole MP plants are used as medicines. The plant leaves, flowers, stems, roots, and fruits are used in the treatment of leprosy, dysentery, vaginal and uterine complaints, inflammations, burning sensation, asthma, leucoderma, fatigue and blood pressure. It is very useful in diarrhea, amoebic dysentery, bleeding piles and urinary infections (Chauhan et al., 2009). It has potent pharmacological activities like antidiabetic, antitoxin, antihepatotoxin, antioxidant and wound healing activities (Meenatchisundaram et al., 2009). Apart from that, many research articles reported its antioxidant, antimicrobial, anti-venom, anticonvulsant, antiulcer, Antihyperglycemic activities (Gandhiraja et al., 2009; Ngo Bum et al., 2004; Chowdhury, 2008; Meenatchisun daram et al., 2009; Aarthi and Murugan, 2011; Elango et al., 2012). These activities are mainly due to the presence of various plant secondary metabolites such as the presence of bioactive constituents like terpenoids, flavonoids, glycosides, alkaloids, quinines, phenols, tannins, saponins and coumarin (Gandhiraja et al., 2009). It was reported that herbs included all the plant parts like leaves, roots, stem, flowers, fruits and seeds which shows various therapeutic activities. Therefore, in the present study, whole parts of MP were selected and compared for one specific activity. Furthermore, cultural condition also affects the constituents present in the plant. Many 
research literatures are evident of that condition and because of that the therapeutic activities are also affects for the particular plant species (Stanton-Geddes et al., 2012; Mohiuddin, 2019). Focusing the same idea, the present study was carried out by selected the said plant from two different cultural conditions, viz., West Bengal (WB) and Tamil Nadu (TN). The composition of biologically active compounds of medicinal plants varies widely depending on the plant species, soil type and on their association with microbes (Zhu et al., 2009; Zhao et al., 2011; Morsy, 2014). Therefore, antimicrobial activity of the given plant collected from two different cultural conditions was selected. As the herbs include various parts of the plant, therefore, it was worth while to select whole plant parts for the effective evaluation of antimicrobial activity.

\section{Materials and Methods}

\subsection{Collection of plant material}

The whole MP plants leaves were collected from two different cultural zones (Srirampur, West Bengal and Hosur, Tamil Nadu) of India. The graphical positions of these two areas were highlighted, i.,e., Srirampur, West Bengal (Longitude $88^{\circ} 20^{\prime} 18.6324^{\prime} \mathrm{E}$ and latitude $\left.23^{\circ} 24^{\prime} 12.0204^{\prime} \mathrm{N}\right)$ and Hosur, TN (77 $49^{\prime} 45.6168^{\prime} \mathrm{E}$ longitude and $12^{\circ} 44^{\prime} 6.4536^{\prime} \mathrm{N}$ latitude) (Figure 1). The plant was identified and authenticated by a plant taxonomist, Dr., P. E Rajshekharan, IIHR, Bengaluru and preserved with the voucher specimens (KCP-PCOG/MP-1/322/2021-22 and KCP-PCOG/MP-2/
322/2021-22) separately in the Department of Pharmacognosy, Krupanidhi College of Pharmacy, Bengaluru, in the herbarium.

\subsection{Preparation of plant crude extracts}

The MP plants were washed with distilled water and air dried at room temperature for 2 weeks. Then, all the parts were separated and coarsely powdered. Labelled them separately and stored in to the plastic sealed cover to resist moisture or microbial contamination till further used for the experimental purpose.

The ethanol, aqueous and hydroalcoholic mixture $(2: 1)$ were used as solvent for the extract preparation. Each $200 \mathrm{~g}$ of powdered drugs were used for the extraction using Soxhlet method at temperature $40^{\circ} \mathrm{C}$ for $4 \mathrm{~h}$. The extracts were filtered separately through whatman filter paper No 42. Further, concentrated to a thick viscous crude from using rotary evaporator (Heidoph 4001 efficient), warmed on water bath at $70^{\circ} \mathrm{C}$ for the aqueous extract and temperature of $50^{\circ} \mathrm{C}$ for methanol, and hydroalcoholic mixture $(2: 1)$ to obtain semi-solid crude extracts.

\subsection{Phytochemical screening}

Phytochemical screening for the MP plant extracts were performed separately to determine the presence of bioactive components such as alkaloids, glycosides, tannins, saponins, terpenoids, flavonoids, and sterols using the method described in the literature (Donkor $e t$ al., 2016; Jagetia and Lalhmangaihi 2018).

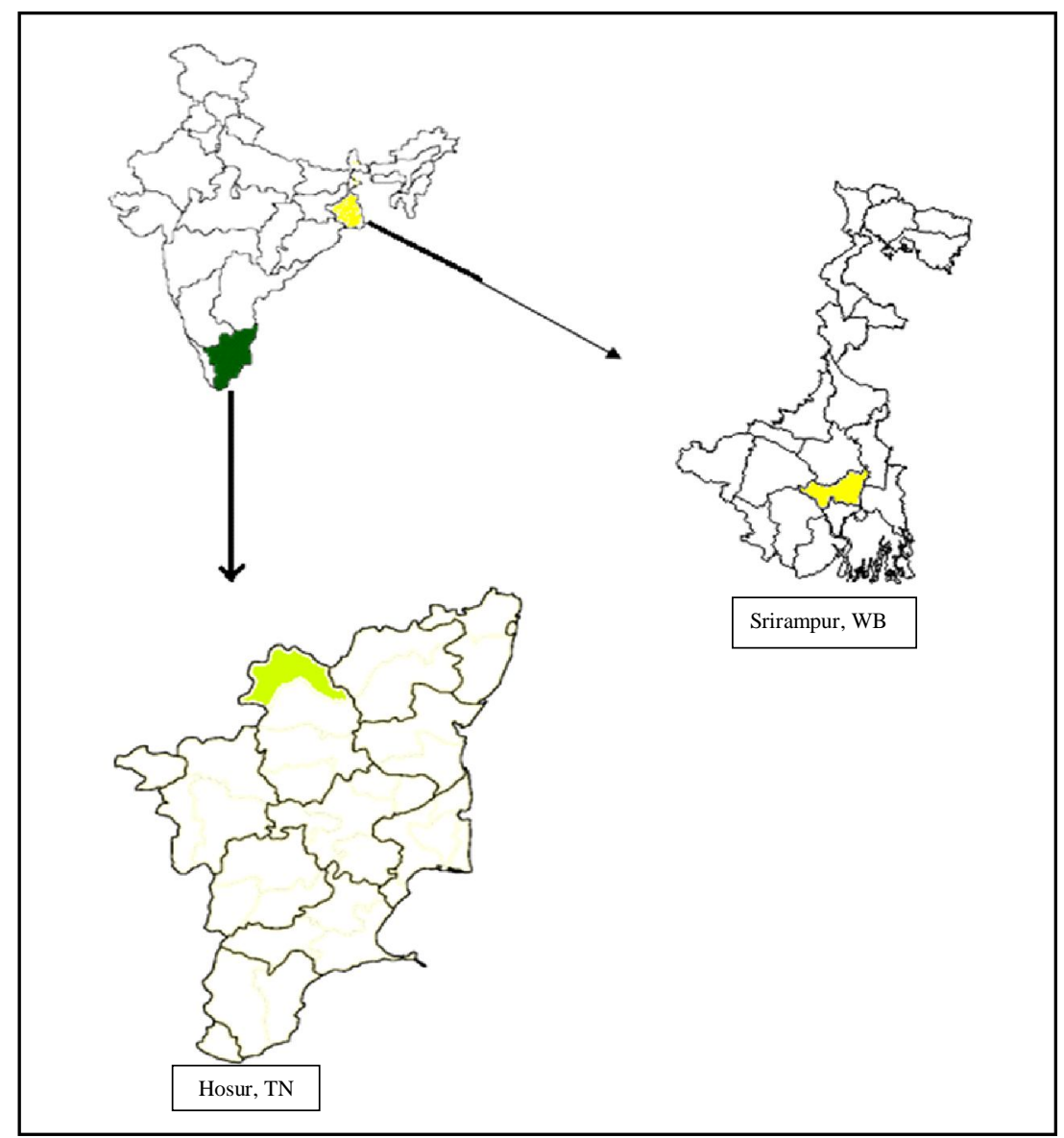

Figure 1: Two different states for MP plant collection. 


\subsection{Test organism}

Four bacterial species were considered, two Gram-positive bacteria such as Bacillus subtilis ATCC 6633, Straphylococcus aureus ATCC 29726, and two Gram-negative bacteria, Pseudomonas aeruginosa ATCC 25619, and Escherichia coli. Clinical isolates of these microorganisms were obtained from the Department of the Microbiology, Maharani College, Bengaluru and they were maintained on nutrient broth at $2^{\circ} \mathrm{C}$.

\subsection{In vitro antimicrobial activity}

The modified agar well diffusion method was applied with $6 \mathrm{~mm}$ sterile borer and the study was conducted as per the method described in the literature (Holder and Boyce, 1994). About $20 \mathrm{ml}$ of molten Mueller Hinton agar was poured into a sterile Petri plate (Himedia, Mumbai, India). The plates were allowed to solidify, after 18 hours (OD adjusted to 0.6), $100 \mu 1$ of above said type strains were transferred onto plate and made culture lawn by using sterile L-rod spreader. After 10 mins, a sterile cork borer was used to make wells on the agar plate with diameter $6 \mathrm{~mm}$. The plant extracts were dissolved in sterile saline and loaded into wells with various concentrations $(25,50$, and $75 \mu \mathrm{g} /$ well). Amoxicillin $(20 \mu \mathrm{g} / \mathrm{ml})$ was used as positive control. The plates were incubated at $37^{\circ} \mathrm{C}$ for one day in a $40 \mathrm{~W}$ florescent light source $(\sim 400 \mathrm{~nm})$. The diameter of the zone of inhibition around the well was measured using antibiotic zone scale (Himedia, Mumbai, India) to find the antibacterial activity.

\subsection{Preparation of plates}

The diluted all the extracts were added separately to the melted and cooled medium in a ratio of 1 part extract sample agent to 9 parts medium $(2.5 \mathrm{ml}$ of plant extract mixed with $17.5 \mathrm{ml}$ of Mueller Hinton agar media for each petri plate). Amoxicillin was used as control for the study.
2.7 Inoculum preparation for minimum inhibitory concentration (MIC) and minimum bactericidal concentrations (MBC)

Inocula for selected test organisms were collected from an overnight agar culture. Inoculum was prepared for both the MIC and MBC experimentation by taking at least three well isolated colonies of the same agar plate culture. The surface of the bacterial colony was touched with a sterile loop and the loop was transferred into a tube containing $5 \mathrm{ml}$ of normal saline and then vortexed. The broth culture was incubated at $37^{\circ} \mathrm{C}$ and monitored for $4 \mathrm{~h}$ until it achieved the turbidity of $0.5 \mathrm{McF}$ arland standard $\left(1.5 \times 10^{8} \mathrm{cfu} / \mathrm{ml}\right)$. The lowest concentration revealed no visible bacterial growth after sub-culturing was taken as MBC.

\subsection{Statistical analysis}

Means and SEM (standard error of the mean) were calculated for the zones of inhibition for the two sets of experiments. These means were statistically compared using the one-way ANOVA to determine the significant different at $p<0.05$. The MIC and MBC were analyzed by one-way analysis of variance of ANOVA.

\section{Results}

\subsection{Yield and phytochemical screening}

The yields of the results from the conducted experiment were tabulated in Table 1. It was observed that highest yield in methanol extract followed by hydroalcoholic and aqueous extracts of the MP plants collected from the two different zones but the yield were varied with the parts. The methanol root extracts showed higher than other parts of MP plant collected from WB zone whereas, the same was showed higher with methanol leaves extract followed by flower, roots and stem extracts of MP plant collected from TN zone (Figure 2).

Table 1: Yield (w/w) of the MP plant in various extracts

\begin{tabular}{|l|c|c|c|c|c|c|c|c|}
\hline \multirow{2}{*}{ Solvents } & \multicolumn{3}{|c|}{ MP extract (WB sample) (w/w) } & \multicolumn{4}{c|}{ MP extract (TN sample) (w/w) } \\
\cline { 2 - 9 } & Roots & Leaves & Flower & Stem & Roots & Leaves & Flower & Stem \\
\hline Methanol & 32.6 & 29.1 & 26.4 & 22.3 & 23.8 & 27.6 & 25.2 & 21.7 \\
Aqueous & 28.2 & 26.8 & 22.6 & 19.4 & 20.8 & 25.0 & 23.2 & 18.7 \\
Hydroalcohol & 30.2 & 28.3 & 24.7 & 20.8 & 22.3 & 26.2 & 24.1 & 20.1 \\
\hline
\end{tabular}

In Figure 2, only higher percentage of yield from both the soil zones are depicted for the MP plant extracts whereas other parts such as flowers, stem are not shown due to less content of yields.

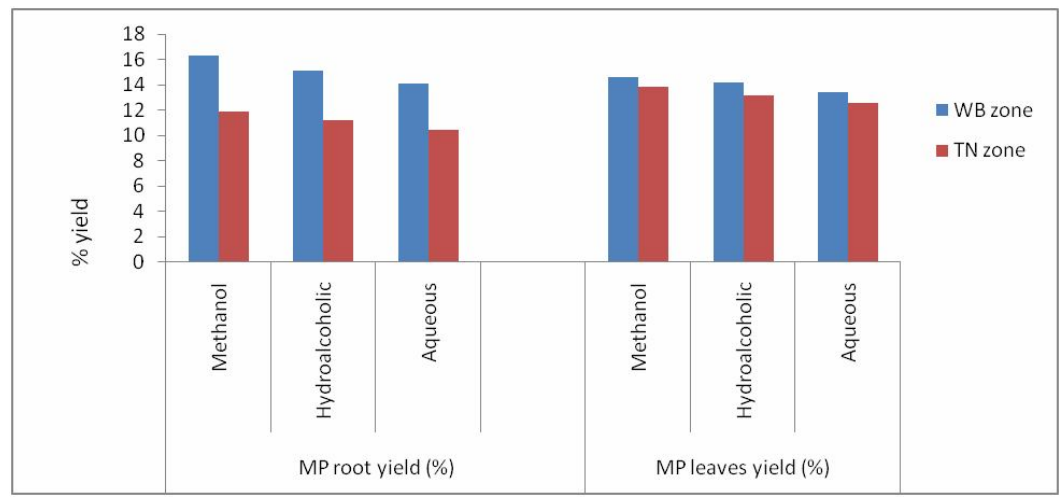

Figure 2: \% yield of the MP samples collected from two different zones. 
Phytochemical screening for all the extracts was carried out separately and result obtained that maximum amount of phytochemical groups are present in the MP plants collected from WB zone than TN zone but the interesting observation recorded that methanol extract followed by hydroalcoholic extract and aqueous extract gave the prominence presence of the bioactive groups such as alkaloids, flavonoids, saponins, sterols, flavonoids, tannins and glycosides which was followed the similar results for the MP samples collected from both the zones. In Table 2, root extracts of WB sample and leaves extracts of $\mathrm{TN}$ samples were depicted.

Table 2: Phytochemical screening of MP extracts collected from WB and TN zones.

\begin{tabular}{|c|c|c|c|c|c|c|}
\hline Phytochemicals & $\begin{array}{c}\text { Methanol } \\
\text { extract (Root) }\end{array}$ & $\begin{array}{c}\text { WB sample } \\
\text { Hydroalcoholic } \\
\text { extract (Root) }\end{array}$ & $\begin{array}{c}\text { Aqueous } \\
\text { extract (Root) }\end{array}$ & $\begin{array}{c}\text { Methanol } \\
\text { extract (Leaves) }\end{array}$ & $\begin{array}{c}\text { TN sample } \\
\text { Hydroalcoholic } \\
\text { extract (Leaves) }\end{array}$ & $\begin{array}{c}\text { Aqueous } \\
\text { extract (Leaves) }\end{array}$ \\
\hline Glycoside & ++ & + & + & ++ & + & + \\
\hline Alkaloids & +++ & ++ & + & ++ & ++ & + \\
\hline Tannins & ++ & + & -- & + & + & -- \\
\hline Flavonoids & ++ & + & + & ++ & + & + \\
\hline Sterols & ++ & + & + & ++ & + & + \\
\hline Phenolics & ++ & + & + & ++ & + & + \\
\hline Saponins & -- & -- & -- & ++ & + & -- \\
\hline Terpenoids & -- & -- & -- & -- & -- & -- \\
\hline Resins & -- & - & -- & -- & -- & -- \\
\hline Proteins & ++ & ++ & + & ++ & + & + \\
\hline Lipids & -- & -- & - & -- & -- & -- \\
\hline
\end{tabular}

$(+++)$ = Prominent; $(++)=$ Medium $;(+)=$ very less present; $(--)=$ Absent

Table 3: Antibacterial activity of MP extracts of two different zones

Zone of inhibition $(\mathbf{m m})$

\begin{tabular}{|c|c|c|c|c|c|c|c|}
\hline Organisms & $\begin{array}{c}\text { Conc } \\
(\mu \mathrm{g} / \mathrm{ml})\end{array}$ & $\begin{array}{l}\text { MP of WB } \\
\text { (Meth. root) }\end{array}$ & $\begin{array}{l}\text { MP of WB } \\
\text { (Hydro- } \\
\text { alcoholic } \\
\text { root) }\end{array}$ & $\begin{array}{l}\text { MP of WB } \\
\text { (Aqu. root) }\end{array}$ & $\begin{array}{c}\text { MP of TN } \\
\text { (Meth. } \\
\text { leaves) }\end{array}$ & $\begin{array}{l}\text { MP of TN } \\
\text { (Hydro- } \\
\text { alcoholic } \\
\text { leaves) }\end{array}$ & $\begin{array}{c}\text { MP of TN } \\
\text { (Aqu. } \\
\text { leaves) }\end{array}$ \\
\hline \multirow[t]{3}{*}{$S A$} & 25 & $12.4 \pm 0.01^{* *}$ & $12.3 \pm 0.13^{* *}$ & $10.2 \pm 0.30^{* *}$ & $11.40 \pm 0.14^{* *}$ & $10.8 \pm 0.11^{* *}$ & $9.0 \pm 0.31^{*}$ \\
\hline & 50 & $14.8 \pm 0.20^{* * *}$ & $13.8 \pm 0.12^{* *}$ & $10.4 \pm 0.21^{* *}$ & $12.32 \pm 0.20^{* * * *}$ & $12.2 \pm 0.13^{* *}$ & $9.2 \pm 0.31^{*}$ \\
\hline & 75 & $17.4 \pm 0.01^{* * *}$ & $15.2 \pm 0.31^{* * *}$ & $11.6 \pm 0.20^{* *}$ & $14.4 \pm 0.11^{* * * *}$ & $14.2 \pm 0.31^{\text {**** }}$ & $10.2 \pm 0.31^{* *}$ \\
\hline \multirow[t]{3}{*}{$B S$} & 25 & $13.2 \pm 0.22^{* *}$ & $11.0 \pm 0.26^{* *}$ & $9.78 \pm 0.14^{*}$ & $10.8 \pm 0.30^{*}$ & $9.6 \pm 0.61^{*}$ & $9.0 \pm 0.31^{*}$ \\
\hline & 50 & $13.7 \pm 0.41^{* * *}$ & $11.4 \pm 0.20^{* *}$ & $10.21 \pm 0.22^{* *}$ & $11.6 \pm 04^{* *}$ & $10.2 \pm 0.21^{* *}$ & $9.8 \pm 0.31^{*}$ \\
\hline & 75 & $14.2 \pm 0.10^{* * *}$ & $12.3 \pm 0.24^{* * *}$ & $11.4 \pm 0.03^{*}$ & $12.0 \pm 31^{* *}$ & $11.1 \pm 0.01^{* *}$ & $10.2 \pm 0.31^{* *}$ \\
\hline \multirow[t]{3}{*}{$E C$} & 25 & $9.82 \pm 0.43^{*}$ & $9.01 \pm 0.30^{*}$ & 8. $03 \pm 0.01^{*}$ & $11.02 \pm 0.22^{* * *}$ & $9.0 \pm 0.30^{*}$ & $8.3 \pm 0.11^{*}$ \\
\hline & 50 & $10.6 \pm 0.13^{* *}$ & $9.33 \pm 0.41^{*}$ & $8.21 \pm 0.24^{*}$ & $11.62 \pm 0.11^{* *}$ & $9.2 \pm 0.31^{*}$ & $9.0 \pm 0.21^{*}$ \\
\hline & 75 & $12.7 \pm 0.30^{* *}$ & $10.8 \pm 0.20^{* *}$ & $9.8 \pm 0.20^{* *}$ & $12.4 \pm 0.04^{* * *}$ & $10.2 \pm 0.31^{* *}$ & $9.2 \pm 0.32^{* *}$ \\
\hline \multirow[t]{3}{*}{$P A$} & 25 & $8.9 \pm 0.36^{*}$ & $7.4 \pm 0.26^{*}$ & $7.0 \pm 0.33^{*}$ & $8.6 \pm 0.51^{*}$ & $7.3 \pm 0.34^{*}$ & $7.2 \pm 0.12^{*}$ \\
\hline & 50 & $9.1 \pm 0.61^{*}$ & 7. $9 \pm 0.26^{*}$ & $7.2 \pm 0.54^{*}$ & $9.10 \pm 0.24^{*}$ & $8.0 \pm 0.01^{*}$ & $8.0 \pm 0.41^{*}$ \\
\hline & 75 & $10.23 \pm 0.14^{* *}$ & $8.10 \pm 0.01^{*}$ & $8.01 \pm 0.20^{*}$ & $9.5 \pm 0.01^{*}$ & $8.2 \pm 0.32^{* *}$ & $8.3 \pm 0.34^{* *}$ \\
\hline $\mathrm{S}$ & 20 & $26.8 \pm 0.01$ & $26.2 \pm 0.03$ & $26.4 \pm 0.11$ & $25.8 \pm 0.22$ & $25.1 \pm 0.32$ & $25.2 \pm 0.02$ \\
\hline
\end{tabular}

The results represent mean \pm standard error of mean $(\mathrm{n}=3) . \mathrm{SA}=$ Straphylococcus aureus, $\mathrm{BS}=$ Bacillus subtilis, EC $=$ Escherichia coli, $\mathrm{PA}=$ Pseudomonas aeruginosa $. \mathrm{S}=$ Amoxicillin. Data were analyzed by one-way ANOVA, followed by Dunnett comparison test against standard Ampicillin. Values were considered significant at $* * * p<0.001 ; * * p<0.01 ; * p<0.05$. 
Leaves, flowers and stems extracts of MP sample (WB zone) showed the presence of alkaloids, flavonoids, sterols, tannins and phenolics medium to less amount whereas, the same also present in less to very less amount in roots, flowers and stems of MP sample collected from TN zone (Results not tabulated).

\subsection{Antibacterial study}

All the three different extracts from two different zones revealed potential antibacterial activity to all the tested micro-organisms. Among them, methanol extract showed higher activity than other two solvent extracts and the same trend followed for both the MP plants collected from the separate zones. In WB sample, methanol root extract showed higher activity in terms of zone of inhibition (in $\mathrm{mm})(17.4 \pm 0.01)$, followed by hydroalcoholic $(15.2 \pm 0.31)$ and aqueous extracts $(11.6 \pm 0.20)$ against $S$. aureus, respectively. Similarly, methanol extract showed maximum inhibition zone with diameter of $12.7 \pm 0.30 \mathrm{~mm}$ in $E$. coli and $10.23 \pm 0.14 \mathrm{~mm}$ in $P$. aeruginosa. The same trend followed for the MP sample collected from TN zone, but the leaves part showed higher activity than root and others. More specifically, methanol extract represented higher antibacterial activity against all bacterial strains (Table 3, Figures 3 and 4). Other extracts were also carried out for antibacterial activity, but the results were not presented in Table 3.

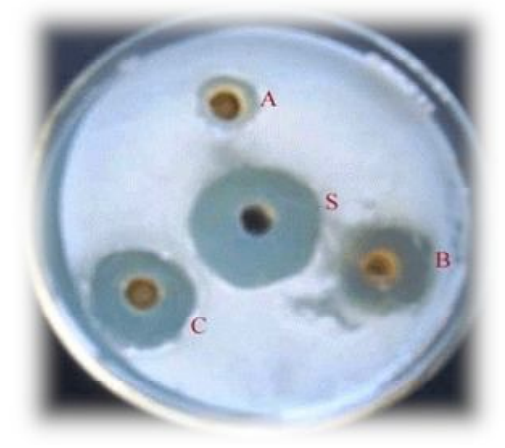

Figure 3: Methanol root extract against SA (WB sample) $\mathbf{S}=$ Standard.

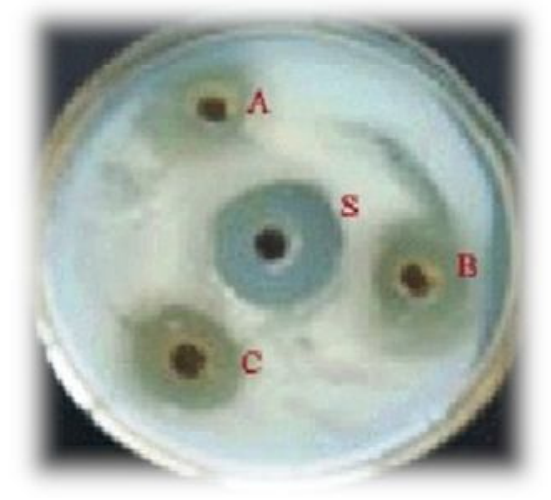

Figure 4: Methanol leaves extract against SA (TN sample) $\mathrm{S}=$ Standard.

$\mathrm{A}=25 \mu \mathrm{g} / \mathrm{ml} ; \mathrm{B}=50 \mu \mathrm{g} / \mathrm{ml} ; \mathrm{C}=75 \mu \mathrm{g} / \mathrm{ml} \mathrm{A}=25 \mu \mathrm{g} / \mathrm{ml} ; \mathrm{B}=50 \mu \mathrm{g} / \mathrm{ml}$; $\mathrm{C}=75 \mu \mathrm{g} / \mathrm{ml}$

The results represent mean \pm standard error of mean $(\mathrm{n}=3)$. $\mathrm{SA}=$ Straphylococcus aureus, $\mathrm{BS}=$ Bacillus subtilis, $\mathrm{EC}=$ Escherichia coli, $\mathrm{PA}=$ Pseudomonas aeruginosa. $S=$ Amoxicillin. Data were analyzed by one-way ANOVA, followed by Dunnett comparison test against standard ampicillin. Values were considered significant at ${ }^{* * * *} p<0.001 ;{ }^{* *} p<0.01 ;{ }^{*} p<0.05$

\subsection{MIC and MBC}

The MIC and MBC were determined against all the causative microorganisms for all the different extracts separately for both the states (WB and TN). Results showed very interesting data where methanol extract showed lower MIC value against $S$. aureus $(19.2$ $\mu \mathrm{g} / \mathrm{ml}$ ) whereas the same was higher with Pseudomonas aeruginosa $(30.6 \mu \mathrm{g} / \mathrm{ml})$ for WB sample. The same trend followed with the TN sample where methanol MP extract showed lower MIC for $S$. aureus $(20.1 \mu \mathrm{g} / \mathrm{ml})$ and higher for Pseudomonas aeruginosa $(34.2 \mu \mathrm{g} / \mathrm{ml})$. Interestingly, MBC values for each case were higher than MIC (Tables 4 and 5, Figure 5).

Table 4: MIC and MBC for the MP extracts for MP sample (WB)

\begin{tabular}{|l|c|c|c|c|c|c|c|c|}
\hline \multirow{2}{*}{ Root extracts } & \multicolumn{2}{|c|}{ Staphylococcus aureus } & \multicolumn{2}{|c|}{ Bacillus subtilis } & \multicolumn{2}{c|}{ Pseudomonas aeruginosa } & \multicolumn{2}{|c|}{ Escherichia coli } \\
\cline { 2 - 9 } & MIC & M BC & MIC & M BC & MIC & M BC & MIC & M BC \\
\hline Methanol extract & $19.2 \pm 0.23$ & $19.8 \pm 0.21$ & $19.3 \pm 0.14$ & $20.8 \pm 0.24$ & $30.6 \pm 0.24$ & $31.7 \pm 0.21$ & $27.6 \pm 0.21$ & $28.2 \pm 0.20$ \\
Hydroalcohol extract & $20.1 \pm 0.20$ & $21.6 \pm 0.13$ & $20.6 \pm 0.13$ & $21.2 \pm 0.20$ & $32.8 \pm 0.03$ & $34.6 \pm 0.03$ & $28.2 \pm 0.33$ & $29.1 \pm 0.13$ \\
Aqueous extract & $22.1 \pm 0.03$ & $23.2 \pm 0.43$ & $21.8 \pm 0.20$ & $23.4 \pm 0.21$ & $34.6 \pm 0.22$ & $34.9 \pm 0.25$ & $29.0 \pm 0.13$ & $29.9 \pm 0.43$ \\
\hline
\end{tabular}

Values are mean of triplicate readings (mean \pm SEM).

Table 5: MIC and MBC for the MP extracts for MP sample (TN)

\begin{tabular}{|c|c|c|c|c|c|c|c|c|}
\hline \multirow[t]{2}{*}{ Leaves extracts } & \multicolumn{2}{|c|}{ Staphylococcus aureus } & \multicolumn{2}{|c|}{ Bacillus subtilis } & \multicolumn{2}{|c|}{ Pseudomonas aeruginosa } & \multicolumn{2}{|c|}{ Escherichia coli } \\
\hline & MIC & MBC & MIC & MBC & MIC & МBC & MIC & MBC \\
\hline Methanol extract & $19.6 \pm 0.11$ & $21.2 \pm 0.43$ & $20.1 \pm 0.21$ & $22.6 \pm 0.14$ & $31.6 \pm 0.03$ & $34.6 \pm 0.33$ & $28.2 \pm 0.43$ & $30.4 \pm 0.11$ \\
\hline Hydroalcohol extract & $21.2 \pm 0.15$ & $23.4 \pm 0.33$ & $21.6 \pm 0.13$ & $23.2 \pm 0.03$ & $32.4 \pm 0.20$ & $36.7 \pm 0.13$ & $28.6 \pm 0.21$ & $32.6 \pm 0.21$ \\
\hline Aqueous extract & $22.6 \pm 0.03$ & $26.0 \pm 0.20$ & $23.1 \pm 0.16$ & $26.4 \pm 0.20$ & $34.2 \pm 0.21$ & $36.3 \pm 0.26$ & $30.2 \pm 0.20$ & $33.7 \pm 0.20$ \\
\hline
\end{tabular}

Values are mean of triplicate readings (mean \pm SEM). 


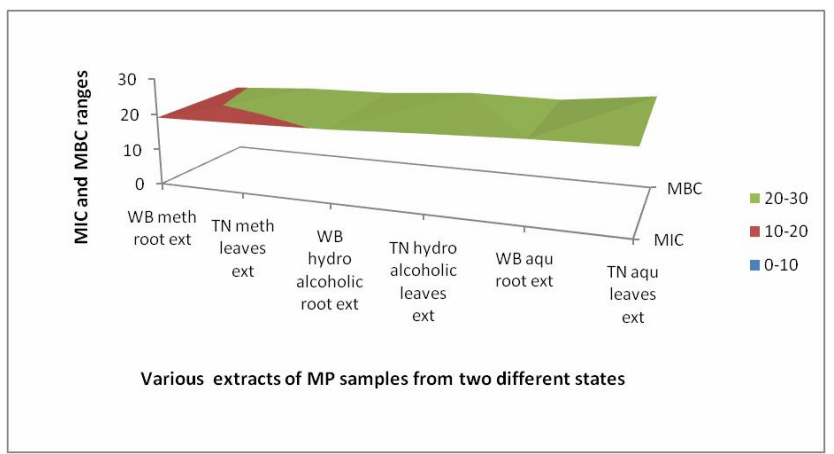

Figure 5: Comparison between different state MP samples of various extracts.

\section{Discussion}

The collected MP whole plants from two different states were extracted with three different solvents (methanol, hydroalcohol and aqueous) and separately collected the extracts. The yield of the crude extracts was estimated (w/w) and revealed higher yield with methanol sample. This was because of the bioactive compounds were maximum dissolved in the methanol sample than other two solvents which resulted higher yield. It was evident that when several solvents were used for the plant extraction, methanol among the solvent provided higher yield than others and also showed that content of total alkaloids, flavonoids were higher than other solvents (Dieu-Hieu et al., 2019; Houda Lezoul et al., 2020). The same trend followed in this research investigation. Thereafter, all the different extracts were investigated for the presence of phytochemicals and revealed the more prominently presence of phytochemicals in methanol extracts from both the state samples. It indicated that the methanol extract contained more bioactive constituents in the dissolved form. In WB sample, the methanolic root extract showed higher yield and also the presence of many active constituents when phytochemical screening was performed, whereas TN sample showed higher yield in methanolic leaves extracts followed by other extracts. This was may be due to the soil nature and soil fertility. It was observed that acidic soil $\mathrm{pH}(5-6)$ enhance the availability of most micronutrients to plants and also favouring the plant growth (Loncaric et al., 2008). In neutral to alkaline soils, although the availability of most macronutrients is increased, but the availability phosphorus and micronutrient availability is generally reduced and their lower levels can adversely affect plant growth (Jiang et al., 2017). The same condition may occur in the present investigation. The MP sample from WB state especially the root showed more accumulation of soil nutrient as a result the availability of phytoconstituents showed higher in root part than other parts. In other hand, the soil nature of TN is neutral to alkaline with $\mathrm{pH}(7-8)$ and, hence accumulation of nutrients in root was less but cumulative accumulation occurred in the leaves part. Therefore, methanol leaves extract showed higher yield and prominent phytochemicals in the same. All the extracts particularly roots, and leaves of MP showed presence of alkaloids, glycosides, flavonoids, tannins, sterols in methanol extract which was similar with the earlier reports (Gandhiraja et al., 2009; Ranjan et al., 2013).

In the present day, bacteria are the most and very hazardous microorganism and Indian traditional medicinal plants are widely used to treat the microbial diseases due to their rich source of antimicrobial activity, less side effects and also economic (Hemalatha et al., 2013). Thereafter, in the present study, amoxicillin was used as standard against selected bacterial strains due to its broad spectrum nature which effective against for both Gram-positive and Gramnegative bacteria. In the present study, antimicrobial efficacy showed by the whole parts of MP plant because of its essential bioactive compounds. It was reported that the group of phytochemicals such as alkaloids, flavonoids, saponins, phenols, tannins, triterpenoids are commonly associated with combating microbial resistance and shows antimicrobial activity (Neog et al., 2013; Thakur et al., 2018; Thakur et al., 2020). The differences in zone of inhibition may be come from the differences in antibacterial activity in that geographical area of plant collection, bacterial strains used, and the parts of the plant used for extraction (Berhanu, 2014). The same trend showed in the present study where root methanol extract showed higher zone of inhibition (WB sample) than the same plant root collected from TN source. Thereafter, leaves methanol extract of MP collected from TN State showed higher zone of inhibition than leaves methanol extract of WB sample. Hence, it indicated that cultural condition had significant role in any pharmacological activities.

Further, minimum inhibitory concentration (MIC) is the highest dilution or least concentration of the extracts that inhibit growth of organisms. MIC is important because it helps in confirming resistance of micro-organism to an antimicrobial agent and it monitors the activity of new antimicrobial agents. Thereafter, the MBC was determined by sub culturing the test dilution (used in MIC) on to a fresh solid medium and incubated further for $24 \mathrm{~h}$. The concentration of plant extract at which completely killed the bacteria is MBC. Interestingly, it was observed that MBC values were higher than that of MIC values and also the Figure 5 demonstrated that confirmation. This indicated that the MP extracts are bacteriostatics at lower concentrations and bactericidal at higher concentrations. The same results were also reported by the earlier researchers (Omar et al., 2010; Sen and Batra, 2012). Henceforth, the results of MIC and MBC of the MP plant extracts suggested that MP can be used to resist and prevent food borne bacteria and food poisoning diseases. S. aureus considered as the one of the most common sources of food borne disease while $B$. substilis, E. coli, and P. aeruginosa produce toxins and other metabolites that induce GI diseases. MP extracts from both the states suppressing microbial growth of all tested bacterial strains which appear to be potentially effective against four bacterial strains (Mostafa et al., 2018).

\section{Conclusion}

Many herbal plant extracts scientifically proved to be potentially effective against wide ranges of bacterial species and natural alternative preventives to control food borne diseases and avoiding healthy hazards. In this study, methanol extract showed maximum antimicrobial activity, followed by hydroalcoholic and aqueous extracts, but the intensity of the effectiveness varied with the concentration while compared with the standard antibiotic saltamoxicillin. Interestingly, cultural condition greatly has impact on potential therapeutic efficacy which revealed in this investigation. This research gives a scientific validation to the fact that bioactive components in the plant MP are extracted substantially in methanol solvent and exhibited highly promising antibacterial inhibitory activity. 


\section{Acknowledgements}

M. Jayalakshmi, Kingsly Dass, Maithili Sinha, Milan Bahadur Chand and Mohammad Ismael Fadil Jowaheer are the students of research work and all of them have equal contribution in the present research investigation. This is an original research article which is submitted by them for publication under the guidance of Dr. Kuntal Das, for the fulfillment of their thesis requirement under Rajiv Gandhi University of Health Sciences, Bengaluru, India.

\section{References}

Aarthi, N. and Murugan, K. (2011). Antimalarial activity and phytochemical screening of ethanolic leaf extract of Phyllanthus niruri and Mimosa pudica. IJPRD, 3(24):198-205.

Berhanu, A. (2014). Microbial profile of Tella and the role of gesho (Rhamnus prinoides) as bittering and antimicrobial agent in traditional Tella (Beer) production. International Food Research Journal, 21(1):357-365.

Chauhan, Bhagirath, S. J. and Davi, E. (2009). Germination, emergence and dormancy of Mimosa pudica. Weed Biology and Management, 9(1):38-45.

Chowdhury, S.A. (2008). Cytotoxicity, antimicrobial and antioxidant studies of the different plant parts of Mimosa pudica. Stamford Journal of Pharmaceutical Sciences, 1(1,2):80-84.

Donkor, A.M.; Mosobil, R. and Suurbaar, J. (2016). In vitro bacteriostatic and bactericidal activities of Senna alata, Ricinus communis and Lannea barteri extracts against wound and skin disease causing bacteria. J. Anal. Pharm. Res., 3(1):46. DOI: 10.15406/japlr.2016. 03.00046 .

Dieu-Hien, T.; Dinh Hieu, N.; Nhat Thuy Anh, T.; Anh Vo, B.; Tuong Ha, D. and Hoang Chinh, N. (2019). Evaluation of the use of different solvents for phytochemical constituents, antioxidants and in vitro anti inflammatory activities of Severinia buxifolia. Journal of Food Quality, 2019; Article ID 8178294. 9 pages.

Elango, V.; Carolin, O. and Raghu, P.S. (2012). Antiulcer activity of the leaf ethanolic extract of Mimosa pudica in rats. Hygeia. J. D. Med., 4 (1):34-40.

Gandhiraja, N.; Sriram, S.; Meena, V.; Srilakshmi, K.; Sasikumar, C. and Rajeshwari, R. (2009). Phytochemical screening and antimicrobial activity of the plant extracts of Mimosa pudica L. against selected microbes. Ethnobotanical Leaflets, 13:618-624.

Hatab, S.; Athanasio, R.; Holley, R.; Rodas Gonzalez, A. and Narvaez-Bravo, C. (2016). Survival and reduction of shiga toxin-producing Escherichia coli in a fresh cold-pressed juice treated with antimicrobial plant extracts. J. Food Sciences, 81:1987-1995.

Hemalatha, M.; Thirumalai, T.; Saranya, R.; Elumalai, E.K. and David, E. (2013). A review on antimicrobial efficacy of some traditional medicinal plants in Tamilnadu. J. Acute Disease, 2:99-105.

Holder, I.A. and Boyce, S.T. (1994). Agar well diffusion assay testing of bacterial susceptibility to various antimicrobials in concentrations non-toxic for human cells in culture. Burns, 20(5):426-429.
Houda Lezoul, N.E.; Belkadi, M.; Habibi, F. and Guillén, F. (2020). Extraction processes with several solvents on total bioactive compounds in different organs of three medicinal plants. Molecules, 25:4672; doi:10.3390/molecules 25204672 .

Jagetia, G.C. and Lalhmangaihi, C. (2018). Phytochemical profiling and antioxidant activity of Lajwanti Mimosa pudica Linn. in vitro. Int. J. Plant. Studies, 1(1):1-13.

Jiang, Y.; Li, Y.; Zeng, Q.; Wei, J. and Yu, H. (2017). The effect of soil pH on plant growth, leaf chlorophyll fluorescence and mineral element content of two blueberries. Acta. Hort., 1180:269-276.

Kirk, M. D.; Angulo, F. J.; Havelaar, A. H. and Black, R. E. (2017). Diarrhoeal disease in children due to contaminated food. Bull. World Health Organ, 95:233-234.

Kumar, N.; Kaur, P.; Das, K. and Chakroborty, S. (2009). Mimosa pudica L.: A sensitive plant. International Journal of Pharmacy and Pharmaceutical Sciences, 1(2):1-7.

Loncaric, Z.; Karalic, K.; Popovic, B.; Rastija, D. and Vukobratovic, M. (2008). Total and plant available micronutrients in acidic and calcareous soils in Croatia. Cereal Res. Commun., 36:331-334.

Meenatchisundaram, S.; Priyagrace, S.; Vijayaraghavan, R.; Velmurugan, A.; Parameswari, G. and Michael, A. (2009). Antitoxin activity of Mimosa pudica root extracts against Naja naja and Bangarus caerulus venoms. Bangladesh J. Pharmacol., 4:105-109.

Mohiuddin, A.K. (2019). Impact of various environmental factors on secondary metabolism of medicinal plants. J. of Pharmacol. and Clin. Res., 7(1):555704. DOI: 10.19080/JPCR.2019.07.555704.

Mostafa, A.A.; Al-Askar, A.A.; Almaary, K.S.; Dawoud, T.M.; Sholkamy, E.N. and Bakri, M.M. (2018). Antimicrobial activity of some plant extracts against bacterial strains causing food poisoning diseases. Saudi Journal of Biological Sciences, 25:361-366.

Morsy, N. M. (2014). Phytochemical analysis of biologically active constituents of medicinal plants. Main Group Chem., 13:7-21. doi: $10.3233 /$ MGC-130117.

Neog, P.; Choudhury, S.; Bhattacharjee, A. and Chetia, P. (2013). A review on ethnomedicinal plants and their active secondary metabolites in antibacterial drug discovery research Pleione., 7:413-423.

Ngo Bum, E.; Dawack, D.L.; Schmutz, M.; Rakotonirina, A.; Rakotonirina, S.V.; Portet, C.; Jeker, A.; Olpe, H.R. and Herrling, P. (2004). Anticonvulsant activity of Mimosa pudica decoction. Fitoterapia, 75(3-4):309314 .

Omar, K.; Geronikaki, A.; Zoumpoulakis, P.; Camoutsis, C.; Sokovic, M.; Ciric, A. and Glamoclija, J. (2010). Novel 4-thiazolidinone derivatives as potential antifungal and antibacterial drugs. Bioorg. and Med. Chem., 18:426-432.

Ranjan, R.K.; Kumar, M.S.; Seethalakshmi, I. and Rao, M.R.K. (2013). Phytochemical analysis of leaves and roots of Mimosa pudica collected from Kalingavaram, Tamil Nadu. Journal of Chemical and Pharmaceutical Research, 5(5):53-55.

Sen, A. and Batra, A. (2012). Evaluation of antimicrobial activity of different solvent extracts of medicinal plant: Melia azedarach Linn. International Journal of Current Pharmaceutical Research, 4(2):67-73. 
Stanton-Geddes, J.; Shaw, R.G; Tiffin, P. (2012). Interactions between soi habitat and geographic range location affect plant fitness. PLoS ONE, 7(5):e36015 https://doi.org/10.1371/journal.pone. 0036015.

Thakur, K.; Anchal, N.; Jaswal S. and Bhatt, A.K. (2018). Evaluation of antimicrobial potential of root extract of Asparagus racemosus Willd. and bark extract of Juglans regia L. against pathogenic bacterial isolates. Ann. Phytomed., 7(2):64-69.

Thakur, K.; Mini Mol, P.; Gawhankar, M.; Gupta, H.; Patil, P.; Salmani, S. and Thakur, M. (2020). Physicochemical characterization and antimicrobial properties of Mahamanjish-thadi kadha: An Ayurvedic formulation. Ann. Phytomed., 9(1):78-90.

Zhao, J.; Shan, T.; Mou, Y. and Zhou, L. (2011). Plant-derived bioactive compounds produced by endophytic fungi. Mini Rev. Med. Chem., 11:159-168.

Zhu, Z; Liang, Z; Han, R. and Wang, X. (2009). Impact of fertilization on drought response in the medicinal herb Bupleurum chinense DC: Growth and saikosaponin production. Ind. Crops Prod., 29:629633.

Kuntal Das, M. Jayalakhsmi, Kingsly Dass, Maithili Sinha, Milan Bahadur Chand and Mohammad Ismael Fadil 